\title{
Laboratory Model Magnetic Fields for the Hainan Island Region
}

\author{
W. B. Hu,* W. Nienaber, and H. W. Dosso \\ Department of Physics, University of Victoria, Victoria, B. C., Canada
}

(Received August 15, 1983)

The behaviour of the electromagnetic fields over the Hainan Island region of the South China Sea is studied using a scaled laboratory analogue model. The model source frequencies used simulate periods of $5 \mathrm{~min}$. to $30 \mathrm{~min}$. in the geophysical scale. To examine the electromagnetic field variations due to the irregular coastlines, the deep ocean, a narrow ocean channel, and an atoll (modelled as a seamount), field components for individual traverses over the model are presented. The coast effect for the bay coastline is visible only for short periods at which the depth of the bay is at least .1 skin depths. The response of the seamount, overlain by a $500 \mathrm{~m}$ depth ocean, differs greatly from the response of an island. Electric current flow over the seamount, confined to this thin layer, produces a quadrature field directly opposite to that for an island. Buried features such as the seamount and depth profile of the deep ocean show the largest in-phase response at the lower frequency where the overlying ocean is much less than .1 skin depth thick.

\section{Introduction}

In recent years there have been several studies of the effects of coastlines and islands on geomagnetic variations using scaled laboratory analogue models to aid in the interpretation of field station results. Examples of laboratory analogue model studies for various islands near continental coastlines are provided by NiEnABER et al. (1979) for the Vancouver Island region, Dosso et al. (1980a) for the British Isles region, Dosso et al. (1980b) for the eastern coastal region of Canada, CHAN et al. (1981a) for the Queen Charlotte Islands region and HEBERT et al. (1983) for the Newfoundland region. These studies examined the channelling of telluric currents in the conductive sea channel between the island and continent, the effect of the nearby deep ocean on the induced electric currents and the associated electric and magnetic fields.

An area along China's coast of much interest for geophysical studies at present is the Hainan Island region in the South China Sea. Considerable

*On leave from the Department of Petroleum Exploration, Jianghan Petroleum Institute, Jiangling, Hubei, People's Republic of China. 
geophysical exploration studies have been carried on in this area. The present work deals with the magnetic field measurements for a laboratory analogue model of the Hainan Island region, including the Gulf of Tonkin, the surrounding ocean, and the coastal regions of the continent. Induced magnetic field components for simulated periods of $5 \mathrm{~min}$. and $30 \mathrm{~min}$. for 6 traverses over the model are discussed. The responses of a narrow channel (Hainan Strait), of the continental coastline, of an island (Hainan Island), and of an atoll (Zhongsha Islands) are examined. In a future work detailed model traverses will be used to produce contour plots and three dimensional views of field components, as well as transfer functions and induction arrows. It is hoped that field station results will be available at a later date to permit a comparison with model results. The comparison should aid in explaining field observations in relation to conducting substructure, ocean depth profile, and the effects of current channelling and distortion by the coastline contours.

\section{Model Description}

Figure 1 shows the simplified map of the region used for constructing the laboratory model. Hainan Island is situated on the continental shelf in a large, shallow bay (Gulf of Tonkin) and separated from the Leizhou Peninsula by a narrow, shallow channel (Hainan Strait). The bathymetric contours show a deep ocean east of Hainan Island and an atoll (Zhongsha Islands) in the deep ocean on the edge of the South China Sea basin.

The laboratory analogue model, the measuring equipment, the source field and end effects have all been described previously (Dosso, 1966, 1973; CHAN et al., 1981a) and will not be repeated here. In the analogue model the scaling conditions used to simulate the geophysical parameters are

$$
\left(f_{m} / f_{g}\right)\left(L_{m} / L_{g}\right)=k \text {, }
$$

and

$$
\left(\sigma_{m} / \sigma_{g}\right)\left(L_{m} / L_{g}\right)=k^{-1}
$$

where the parameters $f, L, \sigma$ represent frequency, length, and conductivity respectively, $k$ is the ratio of the model impedance to the geophysical impedance. The subscript $m$ refers to the model system and the subscript $g$ to the geophysical system. In this model study, graphite is used to simulate the ocean and sediments, and saturated salt water to simulate land. Thus the conductivity scaling is $\sigma_{m} / \sigma_{g}$ $=10^{5} / 3$. With the linear scaling factor chosen to be $L_{m} / L_{g}=10^{-6}, 1 \mathrm{~mm}$ in the model simulates $1 \mathrm{~km}$ in the geophysical scale. These two factors determine the frequency scale factor to be $f_{m} / f_{g}=3 \times 10^{7}$, so that frequencies 


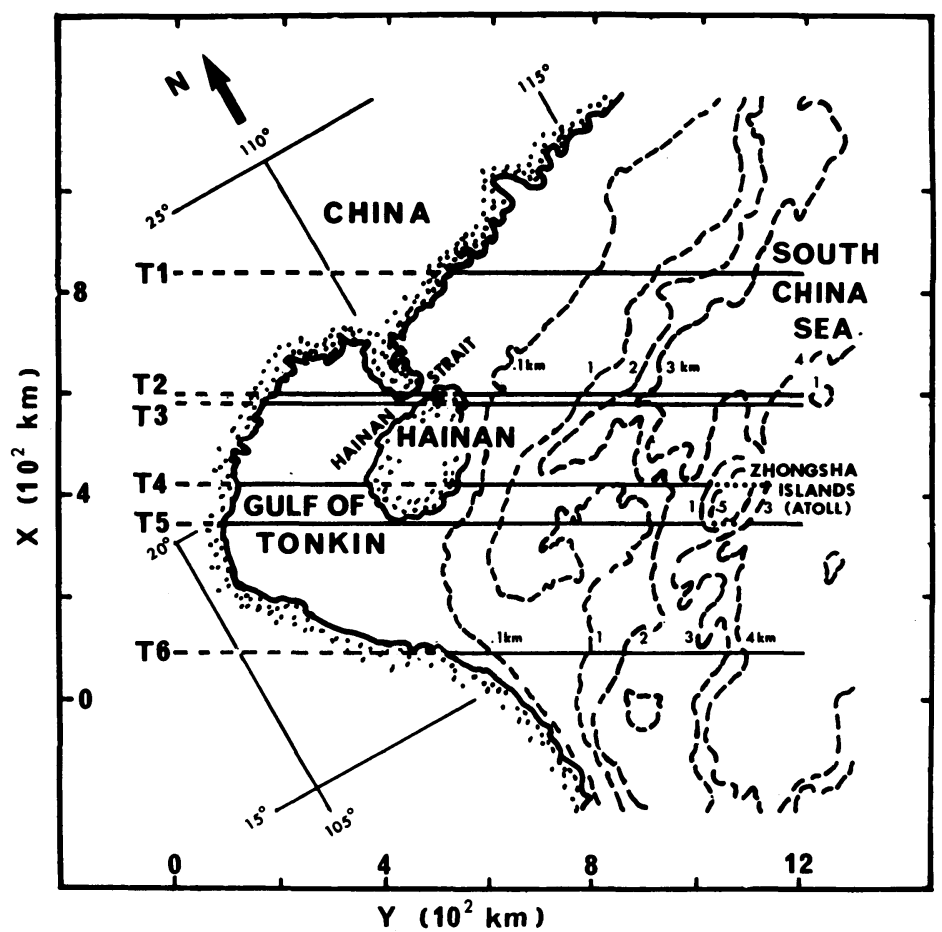

Fig. 1. A simplified map of the Hainan Island region with bathymetric contours, showing location of traverses along which model measurements were recorded. The depth of the model ocean, in the region from the mainland to the $1 \mathrm{~km}$ contour, was increased by $.15 \mathrm{~km}$ to include the effect of the sediments.

of $15 \mathrm{kHz}$ and $90 \mathrm{kHz}$ simulate geomagnetic variations with periods of $30 \mathrm{~min}$. and $5 \mathrm{~min}$. respectively.

The shallow ocean surrounding Hainan Island was simulated in the analogue model using a commercially available laminated graphite foil shaped according to the island and continental coastlines. Several layers of foil and graphite plate of appropriately machined varying thickness were added to simulate the deep ocean depth profile. On the basis of ocean sediment information given by LUDWIG et al. (1979) and NINO and EMERY (1961), it was appropriate to add the equivalent of $150 \mathrm{~m}$ of seawater to account for the sediments in the coastal region extending roughly to the $1 \mathrm{~km}$ ocean depth contour. The method of constructing the model ocean and suspending it in the salt water tank was the same as that discussed previously in earlier work (e.g. Dosso et al., 1980a, 1980b; CHAN et al., 1981a; HeBert et al., 1983). The atoll (Zhongsha Islands) is one of the important features in the present model. The model ocean in the atoll region was machined to follow the sharp depth gradient around the atoll, leaving a very thin layer of graphite directly over the model atoll. Thus the model atoll 
simulates a large flat-top seamount $500 \mathrm{~m}$ below the surface. This model should simulate the actual geophysical case quite well since only a small ring-like coral reef projects above the surface of the ocean (HUXLEY, 1962).

The model was suspended at the surface of the salt water in the tank. The increase in conductivity with depth beneath the oceanic lithosphere in this region is simulated by a $15 \mathrm{~mm}$ graphite plate at a depth of $100 \mathrm{~mm}$ (representing $100 \mathrm{~km}$ ). In the model the highly conducting plate is placed at a sufficiently large depth to yield the same surface field as for the more moderately increasing conductivity with depth in the geophysical case. This method has been used successfully in several models (CHAN et al., 1981a; HEBERT et al., 1983). A fairly uniform horizontal inducing field (RAMASWAMY et al., 1975; NIENABER et al., 1976) was provided by an overhead, oscillating double line current for what is defined as the $E$-polarization of the source field. For this the electric field of the source is in the $x$-direction (Fig. 1) and is roughly parallel to the ocean depth contours. All magnetic field components were measured relative to a reference field, the horizontal field $H_{y}$ of $1 \mathrm{nT}$ at an onshore location at a simulated distance of $400 \mathrm{~km}$ from the coastline.

\section{Discussion of Results}

In the discussion of the results, the magnetic field components are denoted by $H_{x}, H_{y}$, and $H_{z}$. The in-phase and quadrature parts of these components, as well as the amplitude, are presented for $5 \mathrm{~min}$. and $30 \mathrm{~min}$. periods. From a large number of traverses, the six traverses shown in Fig. 1 have been selected for discussion. In all subsequent diagrams, dashed lines show measurements over land, solid lines show measurements over sea and dotted lines show measurements over the atoll. The four features to be examined are the responses of the continental coastlines, of Hainan Strait, of Hainan Island, and of the atoll.

Analogue model results of the in-phase and quadrature parts of magnetic field components for a simulated 5 min. period are shown in Fig.2. A general comment on the response of the field components shown in this figure is that for $5 \mathrm{~min}$. period variations the magnitudes of the anomalies are roughly equal for the in-phase and quadrature parts. The response of the continental coastline for all traverses is generally small as expected for this large bay shaped coastline for the present source field polarization ( $E$-polarization). This effect has been discussed by CHAN et al., (1981b) in studying the response of bay coastlines, and also agrees with the results of Dosso et al. (1980b) for the Gulf of St. Lawrence region of eastern Canada. The response of the peninsula coastline for traverses $\mathrm{T} 2$, and T3 which just by-passes the tip of the peninsula, is expected to be large, since it shows the combined effect of that due to a cape coastline and that due to the narrow Hainan Strait. Current induced in the ocean and deflected by a protruding cape (or peninsula) results in current concentration at the tip of the cape and the expected associated magnetic field enhancement (CHAN et al., 1981b; Dosso et al., 1980b). As well as current concentration due 


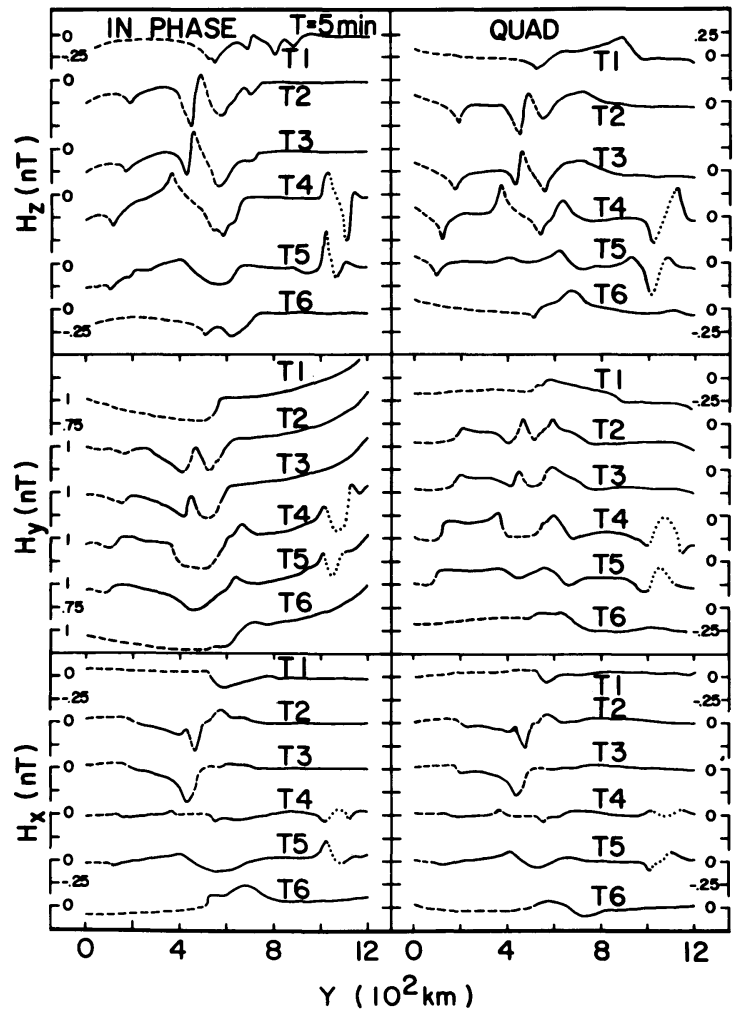

Fig. 2. In-phase and quadrature magnetic fields for traverses over the Hainan Island model for $E$-polarization of a uniform inducing field for $5 \mathrm{~min}$. period.

to the cape effect, there is further current concentration due to the strait effect, the funnelling of induced current into a narrow channel. The direction of the line-current in the strait is roughly $45^{\circ}$ relative to the direction of the electric field of the inducing source, and this current results in anomalies in the vertical and both horizontal magnetic field components as expected in traversing a line current at this angle. The magnitudes of the anomalies in $H_{x}$ and $H_{y}$ are roughly equal as would be expected for a line current having a direction of roughly $45^{\circ}$ relative to the electric field of the source for the present $E$-polarization. The general response of the Hainan Strait observed for T2 agrees with the type of response observed by HEBERT et al. (1983) for the Strait of Belle Isle and the Cabot Strait on the eastern coast of Canada. For Hainan Strait, the direction of $45^{\circ}$ relative to the electric field of the source favors the view of current channelling through the strait since the current in a direction $45^{\circ}$ to the inducing field appears to be much larger than the current that would be induced in the 
strait itself. The conducting model ocean (including sediments) in the Gulf of Tonkin and in Hainan Strait is less than .05 of a skin depth for 5 min. period variations.

The response of Hainan Island is described by the fields for traverses T2-T5 in Fig.2. In general there is a sharp gradient in $H_{z}$, both in-phase and quadrature, over the island with maximum enhancements occurring on both coasts and with a reversal at the center of the island. The anomalous field decreases westwards over the bay, reverses, and shows a sharp anomaly at the mainland. $H_{y}$ and $H_{x}$ show only small gradients in the field over the island except for $H_{x}$ in the vicinity of Hainan Strait. The general behaviour of $H_{x}$ and $H_{y}$ at the east and west coasts of Hainan Island is consistent with the induced current in the Gulf of Tonkin deflected to the east and west around the island, with a large concentration of current in the narrow Hainan Strait. The in-phase part of $H_{y}$ increases seawards as expected for the increasing ocean depth.

The response of the Zhongsha Islands, an atoll, or in our model a flattopped seamount approximately $500 \mathrm{~m}$ (roughly .1 skin depth) below the surface, is shown in traverses T4 and T5. For all three field components the shapes of the field anomalies over the seamount are very similar to those for traverses over Hainan Island except that the quadrature response is the mirror image of that over the island. For the $5 \mathrm{~min}$. period, induced current in the neighbouring deep ocean tends to be deflected around the seamount with perhaps some concentration of current due to channelling in the vertical direction in the shallow ocean directly overhead. These results can be considered in terms of the response of a circular island with large gradient in a deep ocean but with the difference of being overlain by a thin conducting layer of .1 skin depths. Current flow concentrated in this thin layer produces a quadrature response opposite to that expected for an island alone. The change in sign (positive to negative) of in-phase $H_{z}$ in traversing the seamount agrees with the phase change observed by NIENABER et al. (1976) in a model study of model islands, and is explained in terms of two current concentrations deflected around either side of the island. The change in sign of quadrature $H_{z}$ (negative to positive) appears to be associated with a single, phase shifted, line current flowing in the thin ocean over the seamount.

Figure 3 shows the results for the longer period of $30 \mathrm{~min}$. The coast effect at the mainland coastline is small and confined to the quadrature parts and the response of Hainan Strait has greatly decreased with the quadrature parts now showing greater anomalies than the in-phase parts. Hainan Island, too, shows little response at this longer period. The shallow ocean (including sediments) in the Gulf of Tonkin and surrounding Hainan Island for the $\mathbf{3 0}$ min. period variations is approximately .02 skin depth. The in-phase response of the seamount for T4 and T5 for each field component has increased by more than a factor of two. The quadrature response curve of the seamount is small and has reversed to become more like the island effect since, for the $30 \mathrm{~min}$. period, the overlying ocean is now less than .04 skin depths thick. Thus for the $30 \mathrm{~min}$. period the thin overlying ocean is fairly transparent to the inducing 


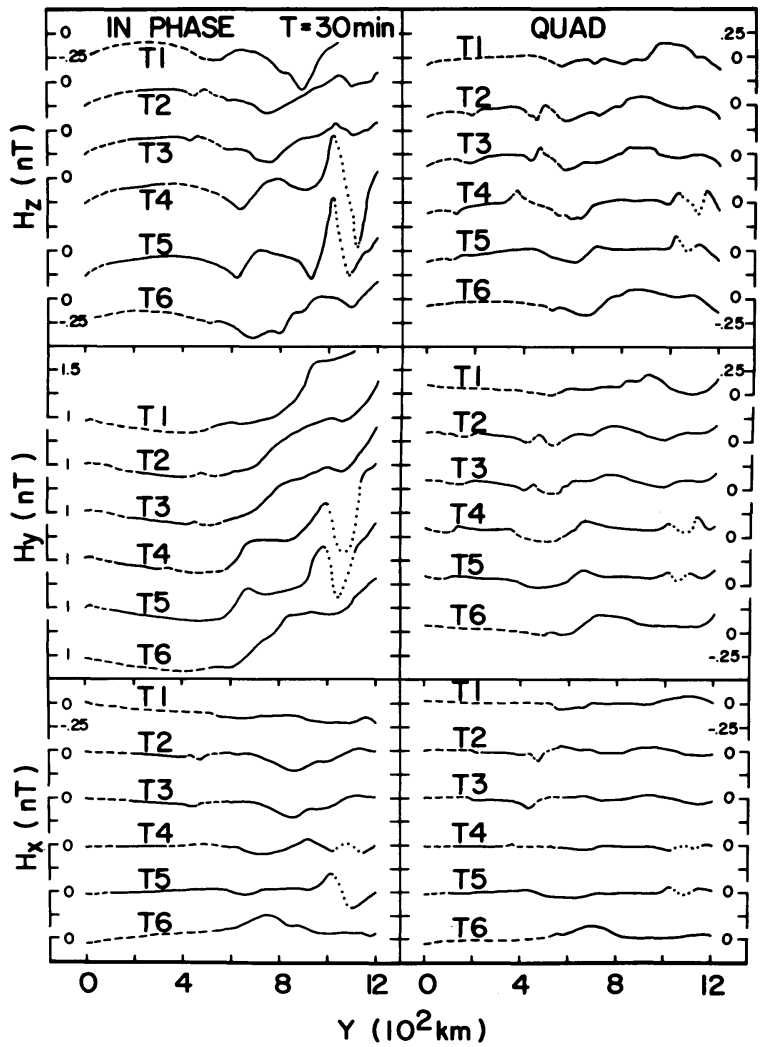

Fig. 3. In-phase and quadrature magnetic fields for traverses over the Hainan Island model for $E$-polarization of a uniform inducing field for $30 \mathrm{~min}$. period.

field and the seamount behaves much like an island alone. A further increase in period would be expected to produce reduced anomalies with a shift to the quadrature part. For similar reasons, the in-phase parts of all three components also show enhanced fields over the ocean westward of the seamount in response to the rapidly changing depth profile.

Figure. 4 shows the amplitude of the field components for source field periods of $5 \mathrm{~min}$. and $30 \mathrm{~min}$. . Traverses $\mathrm{T} 2$ and $\mathrm{T} 3$ for all three components clearly show the response of Hainan Strait for $5 \mathrm{~min}$. period due to current concentration in the narrow channel, flowing in a direction roughly $45^{\circ}$ relative to the $x$-direction of the electric field of the source. The channel effect is strongly frequency dependent, and is hardly observed for $30 \mathrm{~min}$. period. The coast effect, that is, the ratio of the vertical to horizontal component, at the mainland coast is very small (less than .25) for $30 \mathrm{~min}$. period due to the bay effect for the present polarization of the source field. The response of Hainan Island is readily explained in terms of induced currents deflected to the east and to the west around 


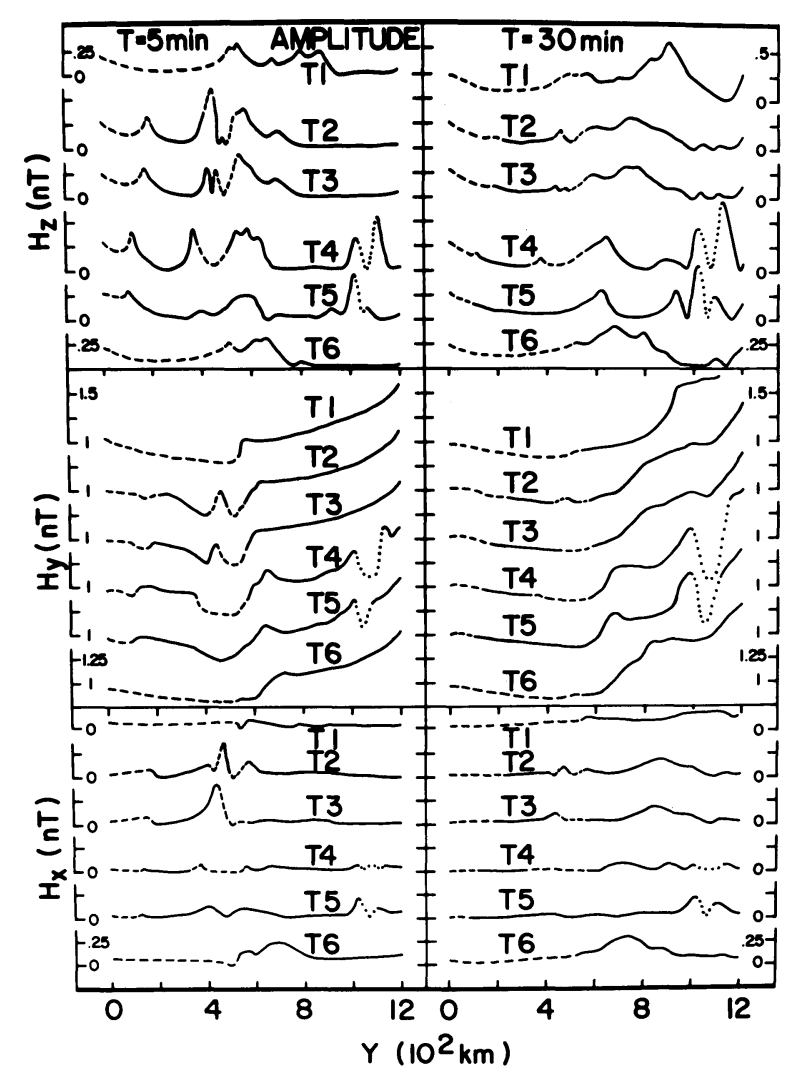

Fig. 4. Amplitudes of the magnetic field components for traverses over the Hainan Island model for $E$-polarization of a uniform inducing field for 5 and $30 \mathrm{~min}$. period.

the island with the resulting increased current density on each side. The difference in the anomalies on either side of the island are due to the effect of the narrow channel to the left of the island and the effect of the deeper ocean on the right. The increased anomalies over the submerged seamount, with increasing period, are primarily due to decreased screening effect of the overlying ocean, with increased period.

\section{Conclusions}

The analogue model results for the Hainan Island region indicate that deflection and local conductive channelling of induced electric current is important for $E$-polarization (northeast-southwest derection of the electric field of source) for the response of Hainan Island, Hainan Strait, and the Zhongsha Island (model seamount) for $5 \mathrm{~min}$. period variations. At $30 \mathrm{~min}$. period, only the seamount 
and the depth gradient of the deep ocean show appreciable response, in fact these responses increase with increasing period. The increased response of the seamount is due to the decreased screening of the overlying ocean with increasing period, while the inversion in the quadrature response curve with frequency can be explained in terms of quadrature current flow constrained within the thin overlying ocean, of the order of .1 skin depths thick, primarily at $5 \mathrm{~min}$. period. The coast effect at the continental coastline, taken as the ratio of the vertical to the horizontal field, is the order of .5 at $5 \mathrm{~min}$. period but much reduced (approximately .2) and hardly visible in the response curve at $30 \mathrm{~min}$. period due to the bay effect for the particular source field polarization studied. This indicates that for $E$-polarization, for frequencies where the bay depth is much less than .1 skin depth, the effect of the ocean should be negligible for field station measurements on the mainland even for locations very near the bay.

In further work, the response of the region for the $H$-polarization (northwestsoutheast) as well as a more detailed dependence on source frequency will be examined. In particular, more detailed study of the response of the seamount as a function of frequency should be of considerable of interest.

The financial support of an N.S.E.R.C. grant and a University of Victoria Faculty Research grant is gratefully acknowledged.

\section{REFERENCES}

Chan, E., H. W. Dosso, and W. NiEnABER, An analogue model study of electromagnetic induction in the Queen Charlotte Islands region, J. Geomag. Geoelectr., 33, 587-605, 1981a.

CHAN, G. H., H. W. Dosso, and L. K. LAW, An analogue model study of electromagnetic induction for cape and bay coastlines, Phys. Earth Planet. Inter., 25, 167-176, 1981 b.

Dosso, H. W., A plane-wave analogue model for studying electromagnetic variations, Can. J. Phys., 44, 67-80, 1966.

Dosso, H. W., A reviews of analogue model studies of the coast effect, Phys. Earth Planet. Inter., 7, 294-302, 1973.

Dosso, H. W., W. NiEnABer, and V. R. S. HutTon, An analogue model study of electromagnetic induction in the British Isles region, Phys. Earth Planet. Inter., 22, 68-85, 1980a.

Dosso, H. W., W. Nienaber, J. A. Wright, J. P. Greenhouse, and R. C. BAiley, An analogue model study of electromagnetic induction in the eastern coastal region of North America, Phys. Earth Planet. Inter., 23, 13-30, 1980b.

Hebert, D., H. W. Dosso, W. Nienabfr, and J. A. Wright, Analogue model study of electromagnetic induction in the Newfoundland region, Phys. Earth Planet. Inter., 32, 65-84, 1983.

HUXLEY, A., Standard Encyclopedia of the World's Oceans and Islands, G P Putnam's \& Sons, New York, 1962.

Ludwig, W. J., N. Kumor, and R. E. Houtz, Profiler-sonobuoy measurements in the South China Sea Basin, J. Geophys. Res., 84, 3505-3518, 1979.

Nienaber, W., H. W. Dosso, L. K. LAW, F. W. Jones, and V. Ramaswamy, An analogue model study of electromagnetic induction for island-continent ocean channels, Phys. Earth Planet. Inter., 13, 169-183, 1976.

Nienaber, W., H. W. Dosso, L. K. LAW, F. W. Jones, and V. Ramaswamy, An analogue 
model study of electromagnetic induction in the Vancouver Island region, J. Geomag. Geoelectr., 31, 115-132, 1979.

NinO., H. and K. O. EMERY, Sediments of shallow portions of East China Sea and South China Sea, Geol. Soc. Am. Bull., 72, 731-762.

Ramaswamy, V., W. Nienaber, H. W. Dosso, F. W. Jones, and L. K. LaW, Numerical and analogue model results for electromagnetic induction for an island situated near a coastline, Phys. Earth Planet. Inter., 11, 81-90, 1975. 